\title{
CONVERGÊNCIAS ENTRE A POLÍTICA EXTERNA DE DILMA ROUSSEFF E O NBD: UMA EXPRESSÃO DO MODELO DE FUNCIONAMENTO DO BRICS ${ }^{1}$
}

\author{
CONVERGENCES BETWEEN DILMA ROUSSEFF'S FOREIGN POLICY AND \\ NBD: AN EXPRESSION OF THE BRICS FUNCTIONING MODEL
}

DOI: $10.5380 /$ cg.v10i1. 75339

\author{
Pedro Vellinho Corso Duval² \\ Felipe Jaeger Andreis3
}

\begin{abstract}
Resumo
O objetivo do presente artigo é a identificação de convergências entre os objetivos afirmados na política externa brasileira durante o mandato de Dilma Rousseff como Chefe de Estado do Brasil e os objetivos que se buscavam ser alcançados a partir da constituição do Novo Banco de Desenvolvimento (NBD) em âmbito do BRICS, bem como entender de que forma o modus operandi do grupo contribuiu para tal consonância. A partir da revisão bibliográfica a respeito dos temas e da análise tanto de discursos da presidente e de ministros das Relações Exteriores quanto das declarações das reuniões de cúpula do BRICS, de 2012 a 2014, e do Acordo Sobre o Novo Banco de Desenvolvimento, foram criadas categorias para classificar os objetivos de ambos os objetos de análise. Posteriormente, realizou-se a comparação entre eles, a partir da qual se pôde concluir que todos os objetivos traçados a partir da criação do NBD, quais sejam: i) a contestação parcial do sistema financeiro internacional; ii) o fortalecimento das economias de países emergentes; e iii) o fortalecimento do grupo enquanto unidade, podem ser verificados na matriz da política externa brasileira no período. Cabe ainda destacar que a referida convergência pode ser compreendida como fruto do modelo de funcionamento do BRICS, ancorado no consenso entre as partes.
\end{abstract}

Palavras-Chave: Política Externa Brasileira; Dilma Rousseff; Novo Banco de Desenvolvimento; BRICS; Multipolaridade.

\begin{abstract}
The purpose of this paper is to identify convergences between the objectives stated in Brazilian foreign policy during Dilma Rousseff mandate as the Brazilian Head of State and the objectives that were sought to be achieved from the constitution of the New Development Bank (NDB) within the BRICS framework, as well as to understand how the group's modus operandi contributed to such consonance. Based on the literature review regarding the themes and the analysis of both speeches by the President and Ministers of Foreign and the statements from the BRICS summit meetings from 2012 to 2014 and the Agreement on the New Development Bank, categories were created to classify the objectives of both objects of analysis. Subsequently, a comparison between them was made, from which it can be concluded that all the objectives outlined from the creation of the NDB, namely: i) the partial contestation of the international financial system; ii) strengthening of the economies of emerging countries; and iii) the strengthening of the group as a unit, can be verified in the matrix of Brazilian's foreign policy in the period. It is also worth noting that this convergence can be understood as a result of the BRICS functioning model, anchored in the consensus between the parties.
\end{abstract}

Keywords: Brazilian Foreign Policy; Dilma Rousseff; New Development Bank; BRICS; Multipolarity.

\footnotetext{
${ }^{1}$ Este artigo está licenciado sob a Licença Creative Commons Attribution (CC BY 4.0), sendo permitido o compartilhamento com reconhecimento da autoria e publicação inicial nesta revista.

${ }_{2}$ Mestrando em Ciência Política pela Universidade Federal do Rio Grande do Sul (UFRGS). E-mail: pedrocorsoduval@hotmail.com. ORCID: https://orcid.org/000o-0001-8321-5768.

3 Graduando de Relações Internacionais na Universidade Federal do Rio Grande do Sul (UFRGS). E-mail: felipe.andreis27@gmail.com. ORCID: https://orcid.org/0000-0002-2177-6022.
} 


\section{INTRODUÇÃO}

A dispersão de poder verificada a partir do término da Guerra Fria viabilizou a emergência de novos polos de poder em âmbito do sistema internacional. O aprofundamento da globalização e da democracia como características fundamentais da nova ordem estabelecida foi decisivo nesse processo, tendo ambas atuado como partes da causa e como catalisadores da dispersão do poder entre os agentes (HOBSBAWM, 1995). Fruto dessa nova conjuntura, o Brasil passa, a partir da virada do século, a reivindicar de maneira mais propositiva seu espaço entre as demais nações, iniciativa sustentada em seu reconhecimento como potência média recém industrializada (CERVO, 2002). O país então vem a ser classificado como Estado "system affecting", sendo as principais características de sua atuação a formação de coalizões e a participação ativa em fóruns multilaterais; bilateralmente, procura intensificar as relações com atores menores e evita relação direta com grandes potências (SENNES, 2003).

Nessa perspectiva, em 2006, à margem da Assembleia Geral das Nações Unidas, Brasil, Rússia, Índia e China se reúnem, iniciando, de maneira informal, uma coordenação entre os países de economia emergente e potencial político. A partir de 2011, é verificada a incorporação da África do Sul ao grupo, consolidando a disposição do atual BRICS. Em 2013, o grupo optou por aprofundar suas ações na esfera financeira a partir da criação do Novo Banco de Desenvolvimento (NBD) (STUENKEL, 2017). O surgimento de tal instituição representou um avanço em termos da consolidação do grupo por se tratar do primeiro bem coletivo proposto desde a sua formação. Ademais, constituiu-se enquanto instrumento de contestação, ainda que parcial, da ordem internacional vigente. A parcialidade é evidenciada por não ser o objetivo de tal iniciativa romper com as bases do sistema, mas sim fortalecer a posição dos envolvidos sobre estas a partir de um aumento de seu próprio grau de autonomia (AGUIAR, 2014).

Cabe, portanto, questionar de que forma os objetivos por trás dessa iniciativa, também chamada de Banco do BRICS, convergem com os objetivos da política externa brasileira no momento de sua concepção, bem como avaliar de que forma o sistema decisório do grupo influencia tal convergência. Trabalha-se a partir da hipótese de que os objetivos que almejam ser alcançados pelo BRICS, a partir da instituição do NBD, estão em consonância com os objetivos externos do Brasil no período, conjectura sustentada pelo próprio modus operandi do grupo, que se lastreia no consenso e na exploração das características convergentes de seus membros. Para atingir esse objetivo, recorreu-se à utilização de dois métodos. Realizou-se a revisão bibliográfica a respeito dos temas para que fossem identificadas as principais conclusões das análises já efetuadas a respeito dos objetivos tanto da política externa brasileira quanto dos objetivos que levaram à constituição do NBD. Posteriormente, procurou-se obter, a partir de fontes primárias, indícios dos principais argumentos sustentados pela literatura. 
Com relação à seleção do material referente à PEB, analisaram-se os discursos de posse da presidente Dilma Rousseff e dos dois ministros que responderam pelo Itamaraty durante o processo de institucionalização do NBD, os embaixadores Antônio Patriota e Luiz Alberto Figueiredo. Compreendendo os discursos de posse como a oportunidade da manifestação dos objetivos da gestão e dos caminhos para alcançá-los (FONSECA, 2017), utilizou-se como critério a seleção dos discursos de posse de Dilma Rousseff na gestão que antecedeu a criação do NBD e os de posse dos ministros, disponíveis no sítio eletrônico da Fundação Alexandre Gusmão. Uma vez que se pretende capturar os objetivos gerais da política exterior, não foram analisados os discursos referentes a encontros bilaterais ou referentes a especificidades temáticas. No entanto, em aberturas de fóruns multilaterais com pautas mais amplas, o país pode se posicionar e expor os seus objetivos, justificando a sua inclusão na análise. Os discursos voltados aos quadros internos do Itamaraty foram selecionados por, de modo semelhante, versarem sobre objetivos gerais e constituírem-se na oportunidade do Chefe de Estado em posicionar-se politicamente diante dos operadores da diplomacia. Feita a seleção, uma leitura crítica dos documentos permitiu o destaque e a organização dos trechos relevantes ao trabalho, em seguida compilados para categorização respaldada pela revisão da literatura especializada na política externa do período.

Com relação à seleção das declarações do BRICS, salientam-se dois critérios. Primeiramente, visto que o propósito da análise é identificar os objetivos por trás da criação do NBD, não cabendo a exploração da manutenção, alteração ou descumprimento de tais diretrizes após seu estabelecimento, as declarações escolhidas foram aquelas resultantes das reuniões de cúpula do BRICS desde o primeiro momento em que o assunto de constituição da nova instituição foi trazido à pauta até o momento de sua efetiva criação, respectivamente, 2012 e 2014, incluindo também o próprio Acordo Sobre o Novo Banco de Desenvolvimento. O critério seguinte, por sua vez, diz respeito à escolha dos trechos para análise: somente foram escolhidos fragmentos que faziam referência direta ao NBD e ao Arranjo Contingente de Reservas (ACR) para então categorizá-los de acordo com o motivo pelo qual sustentam os argumentos favoráveis à criação desses novos mecanismos. Ademais, optou-se pela inclusão de trechos relativos ao ACR em função da inegável complementaridade que este agrega à consolidação do projeto do grupo no período analisado (SCHULZ, 2016). Mesmo que objetivos similares possam ser encontrados em outros trechos das declarações consideradas, estes passam a conter aspectos referentes à posição do BRICS a respeito de questões outras que não fazem parte do escopo da presente análise.

A revisão da literatura e a análise dos discursos que evidenciam a política externa brasileira e das declarações do BRICS no período da consolidação do NBD são apresentadas na seção seguinte. A partir disso, foi possível elencar categorias para classificar os diferentes objetivos de ambos os objetos analisados. Destacou-se, portanto, no caso da política externa brasileira: i) a articulação da estabilidade financeira internacional ao combate à fome e à miséria; ii) a solução de conflitos, paz e cooperação internacional; iii) o fortalecimento da integração dos países emergentes e do 
multilateralismo; e iv) a contestação do sistema internacional. Para o NBD, observam-se: i) a contestação parcial do sistema financeiro internacional; ii) o fortalecimento das economias de países emergentes; e iii) o fortalecimento do grupo enquanto unidade. A terceira seção analisa a convergência de todos os objetivos por trás da criação do NBD com os objetivos elencados na matriz da PEB, assim como a influência do modelo de funcionamento do BRICS, baseado no consenso entre as partes, na sustentação dessa dinâmica. Por fim, a conclusão retoma os argumentos principais expostos ao longo do estudo.

\section{A POLÍtica EXTERNA DE DILMA ROUSSEFF E O NOVO BANCO DE DESENVOLVIMENTO: PRINCIPAIS OBJETIVOS E CARACTERÍSTICAS}

Desde o início das tratativas a respeito da criação do NBD até sua efetiva fundação, foram três as reuniões de cúpula que trouxeram o tema à luz da discussão. A primeira delas correspondia ao quarto encontro do grupo desde seu surgimento, sediada na capital indiana de Nova Déli, em 2012, apenas um ano após a incorporação da África do Sul (STUENKEL, 2017). O Artigo 13 de sua declaração final identifica esse primeiro passo, pontuando que "Consideramos [os chefes de Estado do BRICS] a possibilidade de estabelecer um novo Banco de Desenvolvimento [...]. Nós indicamos nossos Ministros das Finanças para examinar a viabilidade de tal iniciativa [...]" (BRICS, 2012, tradução nossa).

A reunião do ano seguinte, na África do Sul, gera uma declaração exclusiva para tratar sobre a questão do Banco de Desenvolvimento, na qual são anunciadas, dentre outros aspectos, a viabilidade de seu estabelecimento e a vontade dos países para concretizar o projeto (BRICS, 2013). Por fim, na cúpula de 2014, realizada em Brasília, é assinado pelos representantes dos cinco países o Acordo sobre o Novo Banco de Desenvolvimento. Estabelece-se, então, o capital inicial subscrito na quantia de US $\$ 50$ bilhões a ser angariado por meio de contribuições iguais de cada uma das partes, a cidade de Xangai como sede, a abertura da possibilidade de associação a todos os países do Sistema ONU e a proporcionalidade do voto de cada membro a suas parcelas de reservas depositadas no banco (BRICS, 2014).

Diante dessas reuniões, o Brasil, já na gestão de Dilma Rousseff, demonstrou continuidade em sua postura favorável com relação ao fortalecimento do BRICS e na expressão dos seus objetivos externos (CORNETET, 2014). Isso porque se manteve a matriz neodesenvolvimentista da atuação externa de seu antecessor, em que se entende os princípios, prioridades e concepções que ultrapassam as especificidades de um governo. A matriz inaugurada pelo governo Lula substituiu a chamada neoliberal e envolvia o resgate de algumas características do paradigma desenvolvimentista, que predominou enquanto estratégia de inserção internacional dos anos 1930 a 1980 (BOITO JR.; BERRINGER, 2013). Inserida em um contexto de crescente multipolaridade, 
representava uma política externa mais independente, altiva e ativa, caracterizada pela valorização do multilateralismo como instrumento estratégico de defesa dos interesses nacionais, de redução das assimetrias e de democratização do sistema internacional. Também se destaca a manutenção de princípios históricos da política exterior brasileira, como a defesa da autodeterminação dos povos, de não intervenção externa e a valorização da integração regional, sendo adotada, na matriz neodesenvolvimentista, uma visão mais completa e social desses processos, não se limitando aos aspectos comerciais (SILVA, 2015).

Essa matriz encontrou nos BRICS - e em suas iniciativas - espaço para atuação e desenvolvimento, bem como uma oportunidade para ampliar a sua capacidade de inserção internacional em um mundo em transformação. Com o fim da Guerra Fria, o processo de multipolarização foi gradativamente evidenciado por meio do enfraquecimento das instituições que garantiam a sustentação da ordem global unipolar - Organização do Tratado do Atlântico Norte (OTAN), Fundo Monetário Internacional (FMI), Banco Mundial (BM), Acordo Geral de Tarifas e Comércio (AGTC), Conselho de Segurança das Nações Unidas (CSNU). Nesse contexto, o BRICS configura tanto uma consequência da descentralização do poder a nível sistêmico quanto um agente promotor desse processo. Busca-se, a partir de uma estratégia de atuação conjunta, fundamentada na convergência de interesses entre as partes, ampliar a participação delas nas instituições internacionais e, concomitantemente, influenciar as decisões nesses fóruns de discussão. Tal movimento, além de depender em grande parte da postura dos atores em termos de política externa, foi ainda catalisado pelas próprias características intrínsecas a estes em termos de disponibilidade de recursos, tamanho do mercado consumidor, extensão territorial e outros aspectos-chave que fossem capazes de ampliar seu poder de barganha por também atraírem o interesse de outras partes (AGUIAR, 2014).

Cumpre agora aprofundar os objetivos e as características tanto da política externa de Dilma Rousseff quanto dos objetivos de fundantes da iniciativa de maior institucionalização dos BRICS, o Novo Banco de Desenvolvimento. Com o esclarecimento e aprofundamento desses objetivos, bem como a sua classificação, torna-se possível avaliar as suas compatibilidades e a coerência da atuação internacional do país.

\subsection{A POLÍTICA EXTERNA DE DILMA ROUSSEFF}

Apesar da importância da reflexão a respeito do desempenho da política externa no período, importa mais, para o presente trabalho, os seus objetivos per se do que os desdobramentos e resultados de sua execução. Dessa forma, é importante atentar-se aos pronunciamentos iniciais da presidente, que esclarecem os objetivos fundantes à formulação da política exterior para o período. No discurso de posse, proferido na Câmara dos Deputados, houve indicações de tais intenções. Destaca-se, inicialmente, a atenção pelos aspectos econômicos, a partir de uma preocupação com a 
garantia do equilíbrio das contas externas, com a estabilidade financeira internacional, com a proteção contra a concorrência desleal e do fluxo de capitais especulativos, sem esquecer, porém, da centralidade do combate à pobreza e à miséria. Esses destaques e preocupações evidenciam que a política externa do governo Dilma, bem como a matriz na qual se insere, não representa uma ruptura total dos preceitos da matriz neoliberal que a precedeu, mas está mais atenta às insuficiências, às limitações e aos desafios do sistema econômico e financeiro internacional (BRASIL, 2011a). Desse modo, aparece como um eixo estruturante da atuação do país a preocupação com a fome e a miséria, bem como com a estabilidade da economia global, o que aparece acompanhado de uma contestação parcial do sistema econômico internacional. É interessante observar o esforço de abordar esses temas de modo relacionado, com o objetivo de articular a estabilidade financeira internacional ao combate à fome e à miséria. Ou seja, a estabilidade econômica, o enfrentamento à pobreza e o desenvolvimento econômico doméstico eram percebidos como credenciais para a contestação do sistema econômico vigente, mesmo porque "[...] a política externa de um país é mais do que sua projeção na cena internacional. Ela é também um componente essencial de um projeto nacional de desenvolvimento" (BRASIL, formandos).

Observa-se, também, ao longo de todo o discurso de posse, a ênfase no multilateralismo como eixo central para a defesa dos interesses brasileiros. Sennes (2003) oferece uma explicação para esse destaque a partir da condição do Brasil como ator do sistema internacional: enquanto potência média, o país encontra nos fóruns multilaterais a melhor maneira de sustentar seus interesses e de expor as suas posições; por isso o objetivo de utilizá-los, defendê-los, aprofundá-los e democratizálos, sendo reivindicada a reforma dos principais organismos de governança mundial.

Ainda neste pronunciamento, a partir da percepção de um mundo multipolar em consolidação, reafirmou-se os valores clássicos da tradição diplomática brasileira, destacando, em suas palavras, a "promoção da paz, respeito ao princípio de não-intervenção, defesa dos Direitos Humanos e fortalecimento do multilateralismo", além de reafirmar uma postura desarmamentista e de defesa da paz, conferindo um traço de busca pela continuidade e pela estabilidade. Evidencia-se, assim, o objetivo voltado à solução de conflitos, à paz e à cooperação internacional, também presente no discurso dos ministros (BRASIL, 2011c; BRASIL, 2013). Tais traços, porém, não impediram que a postura diplomática fosse conduzida na direção de ampliar as parcerias internacionais, em todos os continentes:

Seguiremos aprofundando o relacionamento com nossos vizinhos sul-americanos; com nossos irmãos da América Latina e do Caribe; com nossos irmãos africanos e com os povos do Oriente Médio e dos países asiáticos. Preservaremos e aprofundaremos o relacionamento com os Estados Unidos e com a União Europeia (BRASIL, 2011a).

Na prática, como apontam os estudos de Saraiva (2014) e Cervo e Lessa (2014), houve uma menor atenção, se comparado aos anos de Lula, à União Europeia e aos Estados Unidos, sendo que, 
com este, as relações foram permeadas por instabilidades. Por isso destaca-se, enquanto objetivo anunciado da PEB, no que tange às parcerias internacionais, a atenção aos países em desenvolvimento, o que é manifestado em diversos discursos (BRASIL, 2011a; BRASIL, 2012a; BRASIL, 2012b; BRASIL, 2013), e ao processo de integração regional, compreendendo-o como elemento estratégico:

A América do Sul seguirá sendo prioridade da política externa do meu governo. Sinalizei essa prioridade ao fazer, à Argentina, minha primeira viagem ao exterior. Não há espaços para discórdias e rivalidades que nos separaram no passado (BRASIL, 2011b).

Essa relação prioritária com a América do Sul, embora não dependente e exclusiva, de fato se concretizou, bem como a atenção aos países em desenvolvimento, o que é evidenciado a partir da atuação ativa do país em fóruns multilaterais com uma postura de representação e defesa do Sul Global, a partir das coalizões e, até mesmo, das relações bilaterais. Dentre estas, destaca-se a relação com a China, a partir de uma maior aproximação política, técnico-científica e consolidando o gigante asiático como principal parceiro comercial do Brasil (SARAIVA, 2014; MILANI, 2018).

Isso posto, entende-se como outra categoria central da ação externa do país o fortalecimento da integração dos países emergentes e do multilateralismo, com ênfase nas relações Sul-Sul. Tais eixos estão presentes nos anúncios dos objetivos externos durante a posse dos Ministros de Estado durante o período, em especial no de Antônio Patriota, que dedicou maior atenção à exposição desses objetivos e da sua interpretação do sistema internacional (BRASIL, 2011c; BRASIL, 2013).

A esses elementos, soma-se nos discursos dos ministros, uma maior ênfase na expressão pública da contestação do sistema internacional. Durante a posse de Dilma e nos discursos públicos de aberturas de fóruns multilaterais, a referência pública a essa contestação não fora tão explícita e destacou, em maior número, a contestação ao sistema econômico. No entanto, esse objetivo externo é evidenciado na oportunidade de seu discurso interno para a formatura dos quadros do Itamaraty:

Reformar o Conselho de Segurança das Nações Unidas não é, portanto, um capricho do Brasil. Reflete a necessidade de ajustar esse importante instrumento da governança mundial à correlação de forças do século XXI. Significa atribuir aos temas da paz e da segurança efetiva importância. Mais do que isso, exige que as grandes decisões a respeito sejam tomadas por organismos representativos e, por essa razão, mais legítimos (BRASIL, 2011b).

Essa contestação, para além de pautas específicas, como a reforma do Conselho de Segurança, expressa-se na defesa do compartilhamento de poder, na crítica aos espaços restritos de decisão internacional e na necessidade de maior protagonismo dos países emergentes.

Permaneceremos atentos para evitar que os círculos decisórios que se formam em torno das principais questões contemporâneas reproduzam as assimetrias do passado, ignorando as aspirações legítimas dos que não os integram. Os G-20s e 
outros agrupamentos restritos só conseguirão consolidar sua autoridade se permanecerem sensíveis aos anseios e interesses dos mais de 150 países que não se sentam em suas reuniões (BRASIL, 2011c).

Destaca-se que, para os objetivos de política externa, o BRICS e sua iniciativa eram compreendidos como ferramentas dessa contestação, o que é ilustrado na declaração da própria presidente em discurso interno ao corpo diplomático: “a recém concluída Cúpula dos BRICS, na China, reafirmou o objetivo dos grandes países emergentes por uma ordem internacional mais democrática e representativa do mundo do século XXI" (BRASIL, 2011b). Desse modo, é importante dedicar-se a compreender os objetivos da criação do NBD para relacioná-lo não apenas aos objetivos do grupo, mas também para identificar a confluência de interesses com os objetivos da PEB.

\subsection{O NOVO BANCO DE DESENVOLVIMENTO}

Viu-se que o BRICS configura tanto uma consequência da descentralização do poder no sistema internacional quanto um agente promotor desse processo, favorecendo a multipolaridade e o multilateralismo. Todos os objetivos sustentados pelo BRICS que deram forma ao projeto de constituição do NBD são derivados dessa mesma matriz favorável ao aprofundamento da multipolaridade (AGUIAR, 2014). De antemão, é importante que se estabeleça uma diferenciação sutil, mas de extrema relevância para a compreensão dos pontos trabalhados mais adiante: existem, sim, objetivos políticos por trás da iniciativa do NBD; contudo o mesmo banco não é idealizado como instrumento de ação política. Nas palavras de Paulo Nogueira Batista Júnior, economista brasileiro e vice-presidente do banco de 2014 a 2017:

A iniciativa de criar o NBD tem um aspecto geopolítico, sem dúvida. Reflete a insatisfação dos Brics com as instituições multilaterais existentes, que demoram a se adaptar ao século XXI e a dar suficiente poder decisório aos países em desenvolvimento. Mas o NBD não é um banco político. O banco se pautará por critérios técnicos para aprovar projetos. O nosso Convênio Constitutivo deixa esse ponto claro. Queremos evitar a excessiva politização das decisões que se observam nas instituições multilaterais existentes (BATISTA JÚNIOR, 2016, p. 179).

Essa estruturação já se configura como uma divergência diante do padrão encontrado especialmente no FMI e, portanto, como um aspecto do primeiro objetivo a ser tratado: $a$ contestação parcial do sistema internacional vigente. Nesse sentido, são elencados ao longo das declarações gargalos que, na visão do grupo, devem ser superados para garantir uma maior estabilidade econômica mundial. É entendido, contudo, que tais entraves não são tratados de maneira adequada por meio dos mecanismos existentes, diante do que o grupo assume uma postura bastante propositiva. Juntamente com o ACR, o NBD representa uma alternativa à ordem atual, uma vez que esta, além de se demonstrar incapaz de formular soluções eficazes para momentos de instabilidade, a exemplo da Crise Financeira de 2008, possui discussões demasiadamente lentas 
quanto a eventuais reformas devido, em última instância, a sua estrutura unipolar (SCHULZ, 2016). Dentre as demais ações práticas que almejam o alcance de tal objetivo, destacam-se ainda o abandono das condicionalidades como pré-requisito de acesso ao crédito e o direcionamento das transações em termos das respectivas moedas nacionais dos países do grupo (MOREIRA JÚNIOR; FIGUEIRA, 2014; SCHULZ, 2016). Aqui, o trecho inicial do Artigo 9 da Declaração de Thekwini, fruto da cúpula de 2013, evidencia de forma satisfatória os pontos elencados:

Países em desenvolvimento enfrentam desafios de expansão de infraestrutura devido a recursos de financiamento de longo prazo e de investimento estrangeiro direto insuficientes, especialmente investimento em estoque de capital. Isso restringe a demanda agregada global. A cooperação do BRICS para um uso mais produtivo dos recursos financeiros globais pode dar uma contribuição positiva para lidar com esse problema (BRICS, 2013, tradução nossa).

Atenta-se também ao caráter complementar da iniciativa com relação à ordem financeira vigente, e por isso o termo "parcial" é igualmente relevante à compreensão de tal objetivo. Não se pretende, dessa forma, criar um projeto de natureza concorrente-conflitiva, mas sim um meio que forneça as bases para que os países emergentes possam aumentar sua influência na ordem econômica internacional (STUENKEL, 2017). Como destaca o Artigo 2 do Capítulo I do Acordo Sobre o Novo Banco de Desenvolvimento:

O propósito do Banco deverá ser a mobilização de recursos para infraestrutura e projetos de desenvolvimento sustentável nos BRICS e em outras economias de mercado emergente e países em desenvolvimento para complementar os esforços existentes de instituições financeiras multilaterais e regionais [...] (BRICS, 2014, tradução nossa).

A partir desse mesmo trecho, é possível identificar outro objetivo relacionado à criação do NBD, qual seja, o fortalecimento das economias de países emergentes. Ficam claras tanto a preocupação com a redução das disparidades entre o Norte e o Sul globais quanto a intencionalidade do grupo em criar mecanismos que operem em prol da reversão desse cenário (STUENKEL, 2017). Investimentos em áreas como infraestrutura e energia são indispensáveis a países que buscam atingir maiores níveis de desenvolvimento econômico uma vez que incidem diretamente sobre a expansão dos setores produtivos. Em última análise, esses investimentos contribuiriam até mesmo para a manutenção de maiores níveis de estabilidade da economia global (MOREIRA JÚNIOR; FIGUEIRA, 2014; PIRES, 2015; STUENKEL, 2017). Ademais, para além das possibilidades que o NBD representa aos países do BRICS, é importante identificar seu potencial de atração sobre países menores. Esse movimento, proporcional ao nível de sucesso desse novo modelo de fomento do desenvolvimento econômico, é importante para que se reforce a legitimidade e a autonomia de ambos, o NBD e o BRICS (SILVA, 2015; STUENKEL, 2017).

O último objetivo a ser abordado diz respeito ao fortalecimento dos BRICS enquanto unidade. $\mathrm{O}$ surgimento do NBD conforma um importante avanço rumo à maior institucionalização 
do grupo, acarretando a incorporação de maiores obrigações por cada uma das partes, sendo reconhecido que "Com base em sólidos princípios bancários, o NBD fortalecerá a cooperação entre nossos países” (BRICS, 2014, tradução nossa). Contudo questionamentos ainda podem surgir quanto ao princípio da proporcionalidade dos votos aliado à preponderância da economia chinesa diante das demais, caso a contribuição de cada membro se diferencie ao longo do tempo. A esse respeito, Moreira Júnior e Figueira (2014) apontam para a improbabilidade de que a China utilize o NBD como instrumento para direcionar recursos econômicos sobre suas demandas exclusivas. A defesa da democratização das instituições financeiras mundiais pelo BRICS aponta para um cenário em que os ideais de desenvolvimento sustentável e de combate às disparidades socioeconômicas figurem cada vez mais como pontos centrais da negociação. Os autores salientam também o próprio esforço chinês em realizar abordagens que expressem a compatibilidade dos interesses de ambas as partes ao iniciar tratativas bilaterais com países de menor dinamismo econômico como um indicativo dessa tendência.

\section{CONVERGÊNCIAS ENTRE A PEB E O NBD E SUA RELAÇÃO COM A DINÂMICA DO BRICS}

Constata-se, a partir da seção anterior, a convergência entre os objetivos que motivaram a criação do banco e os objetivos da política externa brasileira do período de Dilma Rousseff. Era de se esperar, contudo, que os objetivos expressos nesta última também considerassem um número maior de temáticas e, muitas vezes, apresentassem um posicionamento mais firme por não se estar assumindo um compromisso com outras partes, como é o caso do NBD. Dadas essas especificidades, portanto, o exercício comparativo se torna mais claro se as categorias de objetivos identificadas para o NBD forem contrapostas às diretrizes da PEB, e não o contrário.

Inicialmente, tem-se o cunho de contestação parcial do sistema financeiro internacional. No NDB, esse caráter é identificado por meio de sua própria classificação como uma nova instituição financeira internacional ancorada em paradigmas distintos da estrutura do FMI e que é coordenada por novos polos de poder. No que tange à política externa brasileira, o aspecto contestador e revisionista do sistema internacional como um todo, e não só o financeiro, é sustentado com mais veemência a partir do anseio de democratização e transformação das instituições internacionais, embora também não haja indicações de que o país queira promover drásticas alterações à ordem vigente (SCHULZ, 2016). Em seguida, tem-se o fortalecimento das economias de países emergentes como segundo objetivo destacado para a constituição do NBD. Tal aspecto é verificado na matriz da política externa brasileira a partir da priorização do combate à fome e à miséria, matéria em que é identificada pelo governo a grande importância que a ampliação do acesso a recursos financeiros tem na promoção do desenvolvimento e na consequente superação de tais mazelas. Esse fato 
também se relaciona com o maior senso de representação e de responsabilidade do Brasil com o Sul Global e é reforçado pelo propósito do banco, indicado por Stuenkel (2017), em financiar o desenvolvimento, com destaque aos projetos de infraestrutura e de matriz energética, que são demandas dos países em desenvolvimento, contribuindo, assim, com a redução das desigualdades entre norte e sul (SARAIVA, 2014).

Por fim, é verificado o objetivo de fortalecimento do grupo enquanto unidade. Este, ao ser transposto para a política externa brasileira, é o que encontra maior distanciamento em termos de prioridade de atuação internacional do país, embora não invalide a sua coerência com relação ao NBD. À época, o principal ímpeto de aproximação brasileiro era direcionado à América do Sul, dentro de um contexto regional, fato anunciado como intenção da política externa brasileira. Malamud (2011), contudo, a partir da análise dos objetivos brasileiros para o período, das características das políticas que antecederam a presidente e das conjunturas nacional e internacional, fez, à época da publicação do artigo, uma previsão que aponta para a não contradição da ênfase sul-americana com a participação brasileira na criação do NBD: o "Brasil seguirá identificando-se com a sua região, mas não esperará para sair ao mundo” (MALAMUD, 2011, p.177, tradução nossa). A concretização do banco mostra a precisão da previsão, constituindo um esforço do Brasil em intensificar as relações com países de outros continentes, mas não significando o abandono da atenção ou da identidade regional.

Elementos conjunturais internos e externos e eventos da política externa brasileira expostos nos trabalhos de Saraiva (2014) e de Cervo (2014) também indicam a concordância entre a política externa brasileira e as motivações políticas que permearam a criação do NBD, tendo tem relação com a contestação do sistema internacional, em especial o financeiro, e a priorização das relações SulSul. Os Estados Unidos e a União Europeia mostravam indícios, à época da elaboração do banco, de recuperação da crise econômica e financeira que lhes abalara em 2008, reforçando a atuação no G7 e, consequentemente, reduzindo os espaços de atuação e de barganha do Brasil e dos países emergentes no G20 financeiro. O banco, portanto, pode ser encarado como uma resposta destes países, que vai de encontro aos interesses dos países europeus e dos Estados Unidos, que tiveram uma menor atenção da diplomacia brasileira no período. Ademais, a aproximação do Brasil com a China, ocorrida sobretudo em termos comerciais, indica a valorização das parcerias com os emergentes, elemento presente nos valores políticos por trás da criação do NBD. Por fim, a criação de um banco, representando alto grau de institucionalização, reforça o grupo dos BRICS - que recebiam destaque da diplomacia brasileira -, e, por conseguinte, o multilateralismo - eixo central da política externa brasileira na matriz neodesenvolvimentista.

No entanto, cabe ressaltar que as convergências até aqui abordadas não podem ser atribuídas exclusivamente ao mérito da diplomacia brasileira. Elas eram esperadas dada a dinâmica de funcionamento, ancorada no consenso, aproximação e cooperação dos BRICS, e podem ser estendidas a todos os países do grupo. À exceção da China, cuja definição é controversa, todos os 
países são considerados potências médias; portanto, conforme o referido trabalho de Sennes (2003), adotam posturas semelhantes de inserção externa, focalizando nas ações multilaterais, valendo-se das parcerias e coalizões para defesa dos interesses. O gigante asiático, porém, tem características em sua política externa no século XXI que o aproximam dos outros países. Estrutura-se, nesse período, a defesa da paz, da cooperação mútua e do desenvolvimento igualitário, aproximando-se das potências médias do grupo e concordando com os valores políticos articulados para a criação do NBD, de cooperação Sul-Sul, de promoção do desenvolvimento, da valorização do multilateralismo (LANTEIGNE, 2019).

Em estratégia similar à China, a Rússia busca a diversificação de parcerias e a criação de novos polos de poder que se oponham à hegemonia norte-americana. Ademais, o NBD surgia como possibilidade de contorno de suas vulnerabilidades econômicas, em um quadro de maior dificuldade de financiamento à longo prazo, agravada pelas sanções impostas após a crise da Ucrânia, e de dependência dos capitais e da tecnologia europeia (FREIRE, 2014; BIANCO; SECCHI, 2018; PANOVA, 2015). Tal dependência é compartilhada pela África do Sul e pela Índia, que necessitavam compensar os déficits comerciais. Esse último país, além disso, carrega históricos vínculos terceiromundistas, apresentando princípios de autonomia e de autodeterminação como fatores estruturantes de sua política externa desde a sua independência. Isso explica, para além das características de potência média, a reivindicação pelo compartilhamento das tomadas de decisão e a crescente participação em fóruns multilaterais e em iniciativas de integração regional (GANGULY, 2012; SANTOS, 2019). A África do Sul, desde o fim do Apartheid, reintegrou-se à dinâmica regional e reconheceu-se enquanto potência média. Durante a gestão de Jacob Zuma, que governou durante a criação do NBD, tal autorreconhecimento traduziu-se em objetivos externos confluentes às iniciativas do grupo, destacando-se a defesa do multilateralismo, a priorização das relações regionais e Sul-Sul, a busca pela participação no sistema global de governança e a reivindicação da democratização dos organismos internacionais (LANDSBERG, 2015; RIZZI; SCHUTZ, 2014).

Essa estratégia de atuação mediante grupos de coalizão possui um potencial para questionar a estrutura de poder vigente no sistema internacional. Contudo acaba sendo paradoxalmente fragilizada por outra postura inerente às ditas potências emergentes: a defesa da soberania nacional. Dela também é derivado o princípio de decisão por meio de consenso, o que faz com que os países evitem com facilidade tratativas a respeito de assuntos que não lhes convém ou que confronte diretamente seus interesses enquanto nação (SCHULZ, 2016). Outro ponto de fragilidade, inerente ao modo de atuação do grupo, consiste na existência de posicionamentos divergentes entre os membros quanto a questões alheias ao BRICS. Como evidências concretas, pode-se apontar a rivalidade de Índia e China tanto em torno do Mar do Sul da China, no tocante ao controle de rotas comerciais e à determinação das respectivas Zonas Econômicas Exclusivas (ZEE), quanto da penetração de ambos os países no mercado africano de matérias-primas com vistas a atender suas próprias demandas. 
Em contrapartida, pode-se destacar aspectos benéficos do modo de operação pela qual optou o BRICS. Apontando a legalização para definir a forma de institucionalização da qual se vale o grupo, Jesus (2013) analisa como se inserem suas três dimensões, quais sejam os graus de obrigação, precisão e delegação, na dinâmica deste, em que:

A obrigação remete à vinculação de Estados e outros atores por um conjunto de regras ou compromissos, em especial instrumentos juridicamente vinculantes, num momento em que seu comportamento está sujeito ao escrutínio sob regras, procedimentos e discursos gerais do direito internacional. A precisão significa que as regras definem de forma não-ambígua a conduta que requerem, autorizam ou proscrevem. A delegação significa que partes terceiras podem receber autoridade para implementar, interpretar e aplicar as regras; solucionar disputas; e, possivelmente, elaborar mais regras (JESUS, 2013, p. 36).

A conclusão do autor indica que o caso do BRICS se inclina à opção da constituição de mecanismos de cooperação em que os três aspectos supracitados não possuem um elevado grau de influência sobre os membros em função de sua preferência "por maior agilidade na implementação de compromissos, maior flexibilidade para realização de escolhas políticas e maior independência em relação a partes terceiras" (JESUS, 2013, p. 56). Uma vez considerados esses pontos, o NBD surge de forma a ratificar essa dinâmica: mesmo a partir de posicionamentos que por vezes vão pouco além de recomendações, não possuindo em um primeiro momento muitas aplicações, o BRICS é capaz de propor iniciativas concretas a partir da convergência de interesses entre seus membros.

A interpretação aqui proposta é de que, reconhecendo suas vulnerabilidades enquanto atores distintos e a relevância de suas contrapartes para compensá-las a partir de um novo arranjo institucional, Brasil, Rússia, Índia, China e África do Sul preferem iniciar esse processo por meio da cooperação em áreas em que terão de despender menos tempo e recursos para alinhar seus interesses, facilitando as negociações. Outrossim, essa estratégia permite ao grupo impulsionar sua consolidação por agilizar a implementação de propostas referentes a esses consensos, possibilitando também o diálogo entre países que apresentam divergências sobre matérias específicas. Por fim, a atuação do BRICS por meio de consenso garante margem de manobra para que os impactos de eventuais instabilidades sistêmicas ou relacionadas à dinâmica interna dos países membros não afetem diretamente as partes, atuando contrariamente à dispersão do grupo.

\section{CONSIDERAÇÕES FINAIS}

O sistema internacional sofreu profundas transformações com o final da Guerra Fria, o que influenciou o arranjo da política internacional no século XXI. A constituição de um mundo multipolar é parte elementar dessas transformações e se relaciona com a defesa do multilateralismo por parte de grandes potências e de novos players internacionais, o que foi responsável por 
incentivar a emergência de novos grupos de coalizão à margem da dinâmica central da ordem mundial. Estes, por sua vez, passam não só a dar forma à multipolaridade como também evidenciam cada vez mais a contradição presente nas bases fundantes da antiga ordem, as quais tratam a partir de um viés reformatório, mas não revolucionário (AGUIAR, 2014). Os BRICS são parte dessa mudança: ao mesmo tempo que a refletem, também induzem e aceleram essas transformações, o que se expressa não apenas pela retórica do grupo, mas também por suas ações, sendo a iniciativa do NBD retrato da materialização dos princípios e objetivos do grupo.

Nesse contexto de transformações globais, a atuação do Brasil também merece destaque, não apenas por fazer parte dos países BRICS e das economias emergentes, mas também por sua postura internacional no avançar do século XXI. A matriz neodesenvolvimentista inaugurada no governo Lula e mantida por Dilma Rousseff envolvia a ênfase no multilateralismo, o esforço para o deslocamento dos eixos de poder e a diversificação de parcerias, contribuindo com uma nova e mais qualificada condição do país no sistema internacional (CERVO, 2014). A partir de revisão da literatura e da análise de discurso de Dilma Rousseff e dos Ministros das Relações Exteriores do período, foi possível, sinteticamente, caracterizar os principais objetivos da política exterior, para além da defesa do papel de protagonismo internacional do Brasil, a partir das seguintes orientações: i) a articulação da estabilidade financeira internacional ao combate à fome e à miséria; ii) a solução de conflitos, paz e cooperação internacional; iii) o fortalecimento da integração dos países emergentes e do multilateralismo; e iv) a contestação do sistema internacional.

O trabalho confrontou esses objetivos àqueles que motivaram a criação do NBD. Para tanto, também se recorreu à revisão da literatura e à análise de discurso. Novamente em um exercício de síntese, propôs-se a categorização desses objetivos em: i) a contestação parcial do sistema financeiro internacional; ii) o fortalecimento das economias de países emergentes; e iii) o fortalecimento do grupo enquanto unidade. Como esperado, os objetivos da política externa são mais amplos, mas nenhum deles é conflitante com os objetivos mais específicos que estavam por trás da criação do NBD; pelo contrário, todos eles podem ser articulados às aspirações e categorias mais amplas da PEB. A partir da análise de discurso, a única diferença mais significativa foi o objetivo de ampliar as relações na América Latina, que é frequentemente expresso nos discursos referentes à PEB, mas que não tem centralidade nos objetivos do banco - inclusive pela característica e membros dos BRICS. O paralelo que se abre aí, porém, está no objetivo de fortalecer as relações Sul-Sul e garantir maior sustentação aos interesses dos países em desenvolvimento.

Quanto ao balanço entre o potencial propositivo e as dificuldades de constituição do BRICS, ambos refletidos em seu modelo institucional de baixa obrigação, precisão e delegação (JESUS 2013), aponta-se para um saldo final positivo. A opção pelo caminho menos tortuoso para que se inicie a consolidação da atuação do grupo no sistema internacional verifica-se como a mais capaz de retornar os benefícios dessa cooperação no menor prazo possível, destacando-se o NBD como o principal produto dessa dinâmica até o presente momento. Tal dinâmica opera, curiosamente, de 
maneira a incentivar a própria consolidação do grupo, na medida em que os pontos de convergência são afinados e passíveis de se converter tanto em iniciativas mais concretas - que pressupõem a sujeição das partes a termos de maior grau vinculativo - quanto em vetores de amenização das divergências entre os países.

A avaliação da eficiência do referido modus operandi coloca-se, por fim, como alternativa interessante para trabalhos subsequentes. Aqui, expondo sinteticamente, buscou-se analisar a convergência de aspectos apresentados por um dos componentes do grupo BRICS e por uma das instituições a partir dele criada; tal análise acaba, por conseguinte, tornando possível uma inferência a respeito do alinhamento entre o referido ator - o Brasil - e o próprio grupo. Para além disso, compreender como o grau de confluência das partes se materializa ou não em uma agenda mais propositiva por parte do BRICS, bem como identificar a sensibilidade do grupo em relação a movimentos de outros blocos países ou acontecimentos de relevância internacional, configuram-se como passos bastante relevantes para o avanço da pesquisa a respeito do tema.

*Artigo recebido em 21 de julho de 2020, aprovado em 21 de março de 2021.

\section{REFERÊNCIAS}

AGUIAR, Laís Bretones de. A inserção internacional do BRICS na nova ordem do século XXI. 2014. 30 f. Monografia (Especialização) - Curso de Relações Internacionais, Universidade de Brasília, Brasília, 2014. Disponível em: <http://bdm.unb.br/bitstream/10483/8288/1/2014 LaisBretonesdeAguiar.pdf $>$. Acesso em: 21 mar. 2020.

BATISTA JÚNIOR, Paulo Nogueira. BRICS - Novo Banco de Desenvolvimento. Entrevista elaborada por Rubens Rogério Sawaya (PUC-SP). Estudos Avançados, São Paulo, v. 30, n. 88, p. 179-184, set./dez. 2016. Disponível em: <http://www.scielo.br/pdf/ea/v30n88/0103-4014-ea-3088-0179.pdf $>$. Acesso em: 21 mar. 2020.

BIANCO, Matheus Ibelli; SECCHI, Eduardo Tomankievicz. Os Impactos da Vulnerabilidade Econômica Russa na Formulação da sua Política Externa e de Segurança (PES). Revista Perspectiva, v. 11, n. 21, 2018.

BRASIL. Presidente (2011-2016: Dilma Vana Rousseff). Discurso de posse de Dilma Rousseff no Congresso Nacional 01 jan. 2011a. Disponível em: $<$ http://www.brasil.gov.br/governo/2011/o1/leia-integra-do-discurso-de-posse-de-dilmarousseff-no-congresso $>$. Acesso em: 20 jun. 2019.

BRASIL. Presidente (2011-2016: Dilma Vana Rousseff). Discurso na cerimônia de formatura da turma 2009-2011 do Instituto Rio Branco 20 abr. 2011b. Disponível em: <http://www.itamaraty.gov.br/pt-BR/discursos-artigos-e-entrevistas-categoria/presidente-darepublica-federativa-do-brasil-discursos/4666-discurso-da-presidenta-da-republica-dilma- 
rousseff-na-cerimonia-de-formatura-da-turma-2009-2011-do-instituto-rio-branco > Acesso em: 20 jun. 2019.

BRASIL. Presidente (2011-2016: Dilma Vana Rousseff). Discurso durante cerimônia de abertura protocolar da conferência das nações unidas sobre desenvolvimento sustentável. 20 jun. 2012a. <http://www.biblioteca.presidencia.gov.br/presidencia/ex-presidentes/dilmarousseff/discursos/discursos-da-presidenta/discurso-da-presidenta-da-republica-dilma-rousseffdurante-cerimonia-de-abertura-protocolar-da-conferencia-das-nacoes-unidas-sobredesenvolvimento-sustentavel-rio-20>. Acesso em: 21 mar. 2020.

BRASIL. Presidente (2011-2016: Dilma Vana Rousseff). Discurso na abertura da $67^{\mathbf{a}}$ Assembleia Geral das Nações Unidas 25 dez. 2012b. Disponível em: <http://www.biblioteca.presidencia.gov.br/presidencia/ex-presidentes/dilmarousseff/discursos/discursos-da-presidenta/discurso-da-presidenta-da-republica-dilma-rousseffna-abertura-da-67a-assembleia-geral-das-nacoes-unidas-nova-iorque-eua $>$. Acesso em: 21 mar. 2021.

BRASIL. Presidente (2011-2016: Dilma Vana Rousseff). Discurso na cerimônia de abertura da III Cúpula América do Sul-África. 22 fev. 2013. Disponível em: <http://www.biblioteca.presidencia.gov.br/presidencia/ex-presidentes/dilmarousseff/discursos/discursos-da-presidenta/discurso-da-presidenta-da-republica-dilma-rousseffna-cerimonia-de-abertura-da-iii-cupula-america-do-sul-africa-malabo-guine-equatorial $>$. Acesso em: 21 mar. 2021.

BRICS. Delhi Declaration. Fourth BRICS Summit. Nova Déli, 29 mar. 2012. Disponível em: http://www.brics.utoronto.ca/docs/120329-delhi-declaration.html>. Acesso em: 21 mar. 2021.

BRICS. Statement by BRICS Leaders on the Establishment of the BRICS-Led Development Bank. Fifth BRICS Summit. Durban, 27 mar. 2013. Disponível em: <http://www.brics.utoronto.ca/docs/130327-brics-bank.html>. Acesso em: 21 mar. 2021.

BRICS. Agreement on the New Development Bank. Sixth BRICS Summit. Fortaleza, 15 jul. 2014. Disponível em: <http://www.brics.utoronto.ca/docs/140715-bank.html >. Acesso em: 21 mar. 2021.

BOITO JR., Armando; BERRINGER, Tatiana. Brasil: classes sociais, neodesenvolvimentismo e política externa nos governos Lula e Dilma. Rev. Sociol. Polit., Curitiba, v. 21, n. 47, p. 3138, Set. 2013.

CERVO, Amado Luiz. Inserção global no século XXI: a estratégia do Estado logístico. In: CERVO, Amado Luiz; BUENO, Clodoaldo. História da Política Exterior do Brasil. Brasília: Unb, 2002. p. 525-560.

CERVO, Amado Luiz; LESSA, Antônio Carlos. O declínio: inserção internacional do Brasil (20112014). Rev. bras. polít. int., Brasília v. 57, n. 2, p. 133-151, Dez. 2014.

CORNETET, João Marcelo Conte. A política externa de Dilma Rousseff: contenção na continuidade. Conjuntura Austral, v. 5, n. 24, p. 111-150, 2014.

FREIRE, Maria Raquel. A Evolução da Política Externa na Rússia. In: DAEHNHARDT, Patrícia; FREIRE, Maria Raquel (org.). A Política Externa Russa no Espaço Euro-Atlântico: dinâmicas de cooperação e competição num espaço alargado. Dinâmicas de cooperação e competição num espaço alargado. Coimbra: Imprensa da Universidade de Coimbra, 2014. p. 11-29. 
FONSECA, Pedro. Poder e discurso: uma análise de conteúdo do discurso de posse dos ministros de relações exteriores do Brasil (2003-2016). In: CONGRESSO LATINO-AMERICANO DE CIÊNCIA POLÍTICA. 2017.

GANGULY, Sumit. The Genisis of Nonalignment. In: GANGULY, Sumit (org.). India's Foreign Policy: retrospect and prospect. Retrospect and Prospect. Oxford: Oxford, 2012. p. 1-11.

HOBSBAWM, Eric. Era dos Extremos: O breve século XX 1914-1991. São Paulo: Companhia das Letras, 1995 .

JESUS, Diego Santos Vieira de. De Nova York a Durban: o processo de institucionalização do BRICS. Oikos, Rio de Janeiro, v. 12, n. 1, p.32-62, jun. 2013.

LANDSBERG, Chris. Multilateralismo e a ONU na Política Externa da África do Sul. Austral: Revista Brasileira de Estratégia e Relações Internacionais, p. 43-58.

LANTEIGNE, Marc. Chinese foreign policy: an introduction. New York: Routledge, 2019.

MILANI, Carlos. Solidariedade e interesse: motivações e estratégias na cooperação internacional para o desenvolvimento. Curitiba: Appris, 2018.

MOREIRA JÚNIOR, Hermes; FIGUEIRA, Mauro Sérgio. O Banco dos BRICS e os cenários de recomposição da ordem mundial. Boletim Meridiano 47, Dourados, v. 15, n. 142, p.54-62, mar.abr. 2014 .

PANOVA, Victoria V. Rússia nos BRICS: visão e interpretação prática. Semelhanças e diferenças. Coordenação dos BRICS dentro das estruturas de instituições multilaterais. Contexto int., Rio de Janeiro, v. 37, n. 1, p. 47-80, Apr. 2015.

PIRES, Hindenburgo Francisco. Globalização e integração financeira e tecnológica entre os países emergentes: o Novo Banco de Desenvolvimento do BRICS. Geo Uerj, Rio de Janeiro, n. 27, p.283292, out. 2015.

RIZZI, Kamilla Raquel; SCHÜTZ, Nathaly Xavier. Política Externa da Nova África do Sul: reinserção e afirmação regional. Austral: Revista Brasileira de Estratégia \& Relações Internacionais, v. 3, n. 5, p. 181-201, 2014.

SANTOS, Fabio Luis Barbosa dos. Economia política da integração regional: uma comparação entre Índia e Brasil. Estudos Internacionais, v. 7, n. 1, p. 41-62, 2019.

SCHULZ, Juan Sebastián. Los BRICS. El surgimiento de un proyecto de nueva arquitectura financiera y de un nuevo mundo multipolar (2009-2014). 2016. $138 \mathrm{f}$. Dissertação (Mestrado) - Curso de Sociologia, Universidad Nacional de La Plata, Buenos Aires, 2016. Disponível em: <http://www.memoria.fahce.unlp.edu.ar/tesis/te.1226/te.1226.pdf $>$. Acesso em: 21 mar. 2020.

SARAIVA, Miriam Gomes. Balanço da política externa de Dilma Rousseff: perspectivas futuras? Relações Internacionais, Lisboa, n. 44, p. 25-35, dez. 2014.

SENNES, Ricardo. As mudanças na política externa brasileira nos anos 1980: uma potência média recém industrializada. Porto Alegre: Ed. UFRGS, 2003.

SILVA, André Luiz Reis da. Geometria variável e parcerias estratégicas: a diplomacia multidimensional do governo Lula (2003-2010). Contexto Internacional, 37 (1), 143-184. 2015.

STUENKEL, Oliver. BRICS e o futuro da ordem global. Rio de Janeiro: Paz \& Terra, 2017. 